\title{
Forms of Engagement
}

\author{
Mhairi Aitken and Sarah Cunningham-Burley
}

\subsection{INTRODUCTION}

Public engagement (PE) is part of the contemporary landscape of health research and innovation and considered a panacea for what is often characterised as a problem of trust in science or scientific research, as well as a way to ward off actual or potential opposition to new developments. This is quite a weight for those engaging in engagement to carry, and all the more so since PE is often underspecified in terms of purpose. PE can mean and involve different things but such flexibility can come at the price of clarity. It may allow productive creativity but can limit PE's traction. ${ }^{1}$

In this chapter we provide a synthesis of current conceptualisations of PE. We then consider what kinds of publics are 'engaged with' and what this means for the kinds of information exchanges and dialogues that are undertaken. Different forms of PE 'make up' different kinds of publics: engagements do not, indeed cannot, start with a clean sheet - neither with a pure public nor through a pure engagement. ${ }^{2}$ As Irwin, ${ }^{3}$ among others, has noted, PE is a political exercise and this wider context serves to frame what is engaged about. It is therefore all the more important to reflect on the practice of $\mathrm{PE}$ and what it is hoped will be achieved. We argue that clarity and transparency about the intention, practice and impact of PE are required if $\mathrm{PE}$ is to provide an authentic and meaningful tool within health research governance.

\subsection{ENGAGING WITH CRITIQUE}

PE has been a subject of debate for many years, particularly in the Science and Technology Studies literature, through what is termed critical public understanding of science. From Wynne's seminal work onwards, this critique has championed the range of expertise that can come to bear on matters scientific and has provided analytical verve to critiques of the institutional arrangements of both science and PE. Criticisms of top-down models of PE were dominant throughout the 1990 and the 'deficit model of public understanding' was roundly

${ }^{1}$ S. Parry et al., 'Heterogeneous Agendas Around Public Engagement in Stem Cell Research: The Case for Maintaining Plasticity', (2012) Science and Technology Studies, 12(2), 61-80.

${ }^{2}$ K. Braun and S. Schultz, ““... A Certain Amount of Engineering Involved”: Constructing the Public in Participatory Governance Arrangements', (2010) Public Understanding of Science, 19(4), 403-419.

3 A. Irwin, 'The Politics of Talk: Coming to Terms with the 'New' Scientific Governance', (2012) Social Studies of Science, 36(2), 299-320.

4 B. Wynne 'May the Sheep Safely Graze? A Reflexive View of the Expert-Lay Knowledge Divide' in S. Lash et al. (eds), Risk, Environment and Modernity: Towards a New Ecology (London: Sage, 1998). 
debunked not least for suggesting that public ignorance of science was a fundamental cause of loss of trust. This critique played an important role in bringing about a new emphasis on two-way processes of PE that went beyond 'educating the public'. ${ }^{5}$ New commitments to dialogue and engagement - 'the participatory turn' - have become more commonplace and mainstream. ${ }^{6}$ However, as Stilgoe and colleagues have commented, the shift from deficit model approaches to dialogic PE, has been only partially successful:

It has been relatively easy to make the first part of the argument that monologues should become conversations. It has been harder to convince the institutions of science that the public are not the problem. The rapid move from doing communication to doing dialogue has obscured an unfinished conversation about the broader meaning of this activity. ${ }^{7}$

Herein lies further threats to the integrity of PE.

$\mathrm{PE}$ is now a component of much health research where engagement or patient and public involvement is often a funding requirement. This is particularly pronounced in the UK where public understanding and engagement in science has gained increasing institutional traction since the House of Lords report in 2000. For some, the deficit model of public understanding has simply been replaced with a deficit model of public trust, to which 'more understanding' and, even, 'more dialogue' remain a solution. ${ }^{8}$ So, on the one hand the deficit model of publics in need of education about science lingers on, sometimes under the guise of trust. Yet, on the other, we see PE being taken up across sectors - and there is evidence of PE, sometimes, bringing science and its governance to account.

PE can be productive as many commentators have posited. ${ }^{9}$ The task for health research governance is to ensure that participatory practices are not skewed towards institutional ends but allow diverse voices into the policy making process so that they can make a difference to how health research is conducted, regulated and held accountable to the very publics it purports to serve. As Braun and Schultz note:

The question that is increasingly discussed in public understanding of science (PUS) today is not so much whether there is a trend towards participation but what we are to make of it, how to assess it, how to understand the dynamics propelling it, how to systematise and interpret the different forms and trajectories it takes, what the benefits, pitfalls or unintended side-effects of these forms and trajectories are and for whom. ${ }^{10}$

We now turn to consider some of these questions.

\subsection{FORMS OF PUBLIC ENGAGEMENT}

Enthusiasm for, and professed commitment to, PE does not easily translate into meaningful engagement in practice. This is in no small part due to the fact that the term 'public engagement' can be interpreted in many different ways and PE is undertaken for a variety of reasons.

5 M. Kurath and P. Gisler, Informing, Involving or Engaging? Science Communication, in the Ages of Atom-, Bio-and Nanotechnology', (2009) Public Understanding of Science, 18(5), 559-573.

6 Irwin, 'The Politics of Talk'.

7 J. Stilgoe et al., 'Why Should We Promote Public Engagement with Science?', (2014) Public Understanding of Science, 23(1), 4-15, 8 .

${ }^{8}$ S. Cunningham-Burley, 'Public Knowledge and Public Trust', (2006) Community Genetics, 9(3), 204-210; B. Wynne, 'Public Engagement as a Means of Restoring Public Trust in Science - Hitting the Notes, but Missing the Music?', (2006) Community Genetics, 9(3), 211-220.

9 A. Irwin and M. Michael, Science, Social Theory and Public Knowledge (Berkshire: Open University Press, 2003).

${ }^{10}$ Braun and Schultz, '... A Certain Amount of Engineering', 404. 
Key challenges around PE are that the different ideas about its role and value manifest in a variety of purposes and rationales, whether implicit or explicit. PE can be underpinned by normative, substantive or instrumental rationales. ${ }^{11}$ A normative position suggests that PE should be conducted as it is 'the right thing to do' - something that is part and parcel of both public and institutional expectations. An instrumental position regards $\mathrm{PE}$ as a means to particular ends. For example, PE might be conducted to secure particular outcomes such as greater public support for a policy or project. Such a position aligns PE closely with institutional aims and objectives: it promotes public support through understanding and addressing public concerns. A substantive position suggests that the goal of PE is to lead to benefits for participants or wider publics: this can include empowering members of the public, enhancing skills or building social capital. ${ }^{12}$ While these varying rationales are not mutually exclusive, they lead to different understandings and expectations regarding the objectives and role of $\mathrm{PE}$, as well as different ideas of what it means for such processes to be 'successful'.

Rowe and Frewer argue that public involvement as widely understood and imprecisely defined can take many forms, in many different situations (contexts), with many different types of participants, requirements, and aims (and so on), for which different mechanisms may be required to maximize effectiveness (howsoever this is defined)'. ${ }^{33}$ Choosing between different forms requires consideration of purpose and an awareness of the wider context within which engagement is taking place; its effectiveness is more than a matter of method. Academic and practitioner literatures on PE contain many different typologies and classifications of forms of engagement. These often take as their starting point Arnstein's ${ }^{14}$ ladder of public participation. This sets out eight levels of participation, in the form of a hierarchy of engagement. On the bottom rung of the ladder (non-participation), engagement is viewed instrumentally as an opportunity to educate the public and/or engineer support, a common effort when seeking to fill a knowledge deficit or garner social support for a new development. In the middle of the ladder, tokenistic forms of participation include informing and consulting members of the public, where consultation does not involve a two way process, but rather positions the public as having views and attitudes that might be helpful to seek as part of policy development. Again, this is not an unusual mode of engagement in the context of health research. Arnstein suggested that both of these could be valuable first steps towards participation but that they are limited by the lack of influence that participants have. Consultation is described as being a cosmetic 'window-dressing ritual' with little impact, although the extent of impact would depend on how the results of any consultation are subsequently used, rather than being intrinsic to the method itself. The top rungs of the ladder, which move towards empowerment and ownership of process, require redistribution of power to members of the public; while the participatory turn gestures towards such an approach, institutional practices often militate against its enactment.

Arnstein's model has been adapted by a large number of individuals and organisations in developing alternative classification systems and models. This has resulted in a proliferation of typologies, tool kits and models which can be referred to in designing and/or evaluating PE

${ }^{11}$ D. J. Fiorino, 'Citizen Participation and Environmental Risk: A Survey of Institutional Mechanisms', (1990) Science, Technology, \& Human Values, 15(2), 226-243.

${ }_{12}$ J. Wilsdon and R. Willis, See-Through Science: Why Public Engagement Needs to Move Upstream (London: Demos, 2004).

13 G. Rowe and L. J. Frewer, 'Evaluating Public-Participation Exercises: A Research Agenda', (2004) Science, Technology, and Human Values, 29(4), 512-556, 252.

14 S. R. Arnstein, 'A Ladder of Citizen Participation', (1969) Journal of the American Planning Association, 35(4), $216-224$. 
approaches. Aitken has observed that these models, whilst adopting varying terminology and structures, typically follow common patterns:

Each starts with a 'bottom' layer of engagement which is essentially concerned with information provision [...] They then have one (or more) layer(s) with limited forms of public feedback into decision-making processes (consultation), and finally they each have a 'top' layer with more participatory forms of $\mathrm{PE}$ which give greater control to participants. ${ }^{15}$

Forms of engagement classified as 'awareness raising' are essentially concerned with the dissemination of information. Where awareness raising is conducted on its own (i.e. where this represents the entirety of a PE approach) this represents a minimal form of PE. It may even be argued that awareness raising on its own - as one-sided and unidirectional information provision - should not be considered PE. Rowe and Frewer note that at this level, information flow is one-way: there is no involvement of the public per se in the sense that public feedback is not required or specifically sought'. ${ }^{16}$ Awareness raising is limited in what it can achieve, but the focus on increasing understanding of particular issues may be a prerequisite for the deliberative approaches discussed below.

Examples of $\mathrm{PE}$ activities focussed on awareness raising include campaigns by national public health bodies such as Public Health England's 'Value of Vaccines', ${ }^{17}$ or the creation and dissemination of videos and animations to explain the ways that people's health data is used in research. ${ }^{18}$

Consultation aims to gather insights into the views, attitudes or knowledge of members of the public in order to inform decisions. It can involve - to varying degrees - two-way flows of information. Wilcox contends that: 'Consultation is appropriate when you can offer some choices on what you are going to do - but not the opportunity [for the public] to develop their own ideas or participate in putting plans into action'. ${ }^{19}$ Consultation provides the means for public views to be captured and taken into consideration, but does not necessarily mean that these views, or public preferences and/or concerns will be acted on or addressed.

Consultation can be either a one-way or two-way process. In a one-way process, public opinion is sought on pre-defined topics or questions, whereas a two-way process can include opportunities for respondents to reflect on and/or question information provided by those running engagement exercises. ${ }^{2 \circ}$ Such two-way processes can ensure the questions asked, and subsequently the responses given, reflect the interests and priorities of those being engaged. It can also facilitate dialogue and 'deeper' forms of engagement with the aim of characterising, in all their complexity, public attitudes and perspectives.

It is widely recognised that consultation will be best received and most effective when it is perceived to be meaningful. This means that participants want to know how their views are taken into account and what impact the consultation has had (i.e. how has this informed decision-making). Davidson and colleagues caution that: 'Consultation can be a valuable

${ }^{15}$ M. Aitken, 'E-Planning and Public Participation: Addressing or Aggravating the Challenges of Public Participation in Planning?', (2014) International Journal of E-Planning Research (IJEPR), 3, 38-53, 42.

${ }^{16}$ G. Rowe and L. J. Frewer, 'A Typology of Public Engagement Mechanisms', (2005) Science, Technology, ઉ Human Values, 30(2), 251-290, 255 .

${ }_{17}$ Public Health England, 'Campaign Resource Cente', (Public Health England), www.campaignresources.phe.gov.uk/ resources/campaigns.

${ }^{18}$ For example those produced by Understanding Patient Data, 'Data Saves Lives Animations', (Understanding Patient Data), www.understandingpatientdata.org.uk/animations.

19 D. Wilcox, ‘The Guide to Effective Participation', (Brighton: Partnerships, 1994), 11.

2o Rowe and Frewer, 'Typology of Public Engagement'. 
mechanism for reflecting public interests, but can also lead to disappointment and frustrations if participants feel that their views are not being taken seriously or that the exercise is used to legitimise decisions that have already been made'. ${ }^{21}$ Again, we see that choice of method is no guarantee of meaningful engagement in terms of influence on the practices of research and its governance.

Approaches taken to consultation include: public consultations where any member of the public is able to submit a written response; surveys and questionnaires with a sample which aims to be representative of the wider population (or key groups within it); and, focus groups, deliberative engagement or community-based participatory methods to engage more deeply with communities to shape both research processes and outcomes.

Approaches to PE that can be classified under the heading of empowerment are those that would be positioned at the top of Arnstein's ladder of participation. These approaches involve the devolution of power to participants and the creation of benefits for participants and/or wider society. This can be achieved through public-led forms of engagement where public members themselves design the process and determine its objectives, topics of relevance and scope or through partnership approaches. ${ }^{22}$ It might also be achieved through engagement approaches that bring together public members in ways that build relationships and social capital that will continue after the engagement process ends. ${ }^{23}$ Both invited and uninvited ${ }^{24}$ forms of engagement can involve empowerment, so it is possible to engineer a flattening of hierarchies of knowledge and expertise as well as respond to efforts of publics to come together to define and debate issues of concern.

Empowering forms of engagement can lead to outcomes of increased relevance to communities and that most accurately reflect public interests and values. However, they can also be more expensive than traditional forms of engagement, given that they necessitate more open and flexible timeframes and may require extra skills related to facilitation and negotiation. Certainly, they may confront the more uncomfortable social, political and economic consequences and drivers of health research.

One example of engaging with some of the wider issues raised by health data and research is the dialogue commissioned by the Scottish Government to deliberate about private and third sector involvement in data sharing. ${ }^{25}$

While a hierarchical classification, such as Arnstein's, serves to highlight the importance of how the public are positioned in different modes of engagement, each broad approach described above can add different value and play important roles in PE. In practice it may be most appropriate for PE to use a range of methods reflecting different rationales and objectives. Rather than conceptualising them hierarchically, it is more helpful to think of these methods as overlapping and often working alongside each other within any PE practice or strategy.

${ }^{21}$ S. Davidson et al., 'Public Acceptability of Data Sharing between the Public, Private and Third Sectors for Research Purposes', (2013) Social Research Series (Edinburgh: Scottish Government), 4.30.

${ }^{22}$ L. Belone et al., 'Community-Based Participatory Research Conceptual Model: Community Partner Consultation and Face Validity', (2016) Qualitative Health Research, 26(1), 117-135.

${ }^{23}$ INVOLVE, 'People and Participation: How to Put Citizens at the Heart of Decision-Making' (INVOLVE, 2005), www.involve.org.uk/sites/default/files/field/attachemnt/People-and-Participation.pdf.

${ }^{24}$ P. Wehling, 'From Invited to Uninvited Participation (and Back?): Rethinking Civil Society Engagement in Technology Assessment and Development', (2012) Poiesis \& Praxis, 9(1), 43-60.

25 Davidson et al., 'Public Acceptability'. 


\subsection{TYPES OF PUBLICS}

$\mathrm{PE}$ and involvement professionals, policy documents and critical scholars increasingly refer to 'publics' as a way to problematise and differentiate within and between different kinds of public. The adoption of such a term signifies that publics are diverse and that we cannot talk of a homogeneous public. However, beyond that, the term may obscure more than it reveals: what kinds of publics are we talking about when we talk about PE, and how are these related to particular forms of engagement? As Braun and Schultz note "“The public," we argue, is never immediately given but inevitably the outcome of processes of naming and framing, staging, selection and priority setting, attribution, interpellation, categorisation and classification' ${ }^{26}$ How members of 'the public' are recruited is more than a practical matter: the process embodies the assumptions, aims and priorities of those designing the engagement.

On the whole, publics are constructed or 'come into being' within PE practices rather than being self-forming. As with types of PE, different categorisations of publics have been developed. Degeling and colleagues highlight three different types: citizens (ordinary people who are unfamiliar with the issues, a kind of pure public); consumers (those with relevant personal experience, a kind of affected public) and advocates (those with technical expertise or partisan interests). ${ }^{27}$ And each of these was linked to different types of PE. Citizens were treated as a resource to increase democratic legitimacy; consumers were directed to focus on personal preferences; advocates were most commonly used as expert witnesses in juries - directly linked to policy processes. However, overall the 'type' of public sought was often not explicit, and their role not specified.

Braun and Schultz ${ }^{28}$ elaborate a four-fold distinction: the general public, the pure public, the affected public and the partisan public. Different PE methods serve to construct different kinds of publics. The general public is a construct required for opinion polls and surveys; pure publics for citizen conferences and juries; affected publics for consultative panels; partisan publics for stakeholder consultations. However, as with the different types of PE, in practice there will be overlaps across these dimensions and subject positions will shift as expertise is crafted through the processes of engagement and facilitation. ${ }^{29}$ Different types of expertise are presumed here too: the general public gives policy makers knowledge about people's attitudes; the pure public creates a 'mature' citizen who becomes knowledgeable and can develop sophisticated arguments; affected publics bring expertise to 'educate' the expert - very common in health research regulation; and a partisan public may be deliberately configured to elicit viewpoints 'out there' in society to assess the 'landscape of possible argument'. $3^{30}$

Types of PE and the categorisation of different publics involve processes of inclusion and exclusion and the legitimacy of PE can easily be challenged because of who participates: some voices may be prioritised over others, and challenges may be made to participants' expertise. We turn now to a case study of how PE is being enacted in one area of health research to explore how we might deal with these problematics of how and who.

${ }^{26}$ Braun and Schultz, ‘. . A Certain Amount of Engineering', 406

${ }^{27}$ C. Degeling et al., 'Which Public and Why Deliberate? - A Scoping Review of Public Deliberation in Public Health and Health Policy Research', (2015) Social Science \& Medicine, 131, 114-121.

${ }_{28}$ Braun and Schultz, '... A Certain Amount of Engineering'.

${ }^{29}$ A. Kerr et al., 'Shifting Subject Positions: Experts and Lay People in Public Dialogue', (2007) Social Studies of Science, 37(3), 385-411.

3० Braun and Schultz, '... A Certain Amount of Engineering', 414 . 


\subsection{PUBLIC ENGAGEMENT IN DATA INTENSIVE HEALTH RESEARCH: PRINCIPLES FOR AN INCLUSIVE APPROACH}

The digitisation of society has led to an explosion of interest in the potential uses of more and more population data in research; this is particularly true in relation to health research. ${ }^{31}$ However, recent years have also brought a number of public controversies, particularly regarding proposed uses of health data. Two high profile examples from England are the failed introduction of the care.data scheme to link hospital and GP records ${ }^{32}$ and Google Deep Minds' involvement in processing health data at an NHS Trust in London. ${ }^{33}$ The introduction of Australia's National Electronic Health Record Systems (NEHRS) also floundered, demonstrating the importance of taking account how such programmes reflect, or jar, with public values. ${ }^{34}$ Such controversies have drawn attention to the importance of engaging with members of the public and stakeholders to ensure that data are used in ways which align with public values and interests and to ensure that public concerns are adequately addressed.

The growing interest in potential uses of population data, and the increasing recognition of the importance of ensuring a social licence for their use, have resulted in considerable interest in understanding public attitudes and views on these topics. ${ }^{35}$ With the expansion of research uses of (health) data there has been a growing interest in public acceptability. As Bradwell and Gallagher have suggested, 'personal information use needs to be far more democratic, open and transparent' and this means 'giving people the opportunity to negotiate how others use their personal information in the various and many contexts in which this happens'. ${ }^{6} \mathrm{PE}$ is seen as key to the successful gathering and use of health data for research purposes.

As a recent consensus statement on PE in data intensive health research posits, there are particular reasons to promote $\mathrm{PE}$ in data intensive health research ${ }^{37}$ including its scale - here the wider public is an 'affected' public and the distance is increased between researchers and those from whom data are gathered, thus requiring a new kind of social licence. ${ }^{38}$ This requires novel thinking about how best to engage publics in shaping acceptable practices and their effects.

As well as recognising diverse practices, aims and effects, and building reflexive critique into $\mathrm{PE}$ for health research regulation and governance, we need to articulate some common commitments that can help steer a useful path through this diversity and thereby challenge criticisms of institutional capture and tokenism. ${ }^{39}$ These commitments must include clarity of purpose and transparency, which will help deal with the challenges of multiple but often

${ }^{31}$ K. McGrail et al., 'A Position Statement on Population Data Science: The Science of Data about People', (2018) International Journal of Population Data Science, 3(1), 1-11.

${ }^{2}$ P. Carter et al., 'The Social Licence for Research: Why care.data Ran into Trouble', (2015) Journal of Medical Ethics, 41(5), 404-409.

33 J. Powles and H. Hodson, 'Google DeepMind and Healthcare in an Age of Algorithms', (2017) Health and Technology, 7, 351-367.

34 K. Garrety et al., 'National Electronic Health Records and the Digital Disruption of Moral Orders', (2014) Social Science \& Medicine, 101, 70-77.

35 M. Aitken et al., 'Public Responses to the Sharing and Linkage of Health Data for Research Purposes: A Systematic Review and Thematic Synthesis of Qualitative Studies', (2016) BMC Medical Ethics, 17(1), 73; Social Research Institute, 'The One-Way Mirror: Public Attitudes to Commercial Access to Health Data', (Wellcome Trust, 2016).

${ }^{6}$ P. Bradwell and N. Gallagher, We No Longer Control What Others Know about Us, But We Don't Yet Understand the Consequences ...The New Politics of Personal Information (London: Demos, 2007), pp. 18-19.

37 M. Aitken et al., 'Consensus Statement on Public Involvement and Engagement with Data Intensive Health Research’, (2019) International Journal of Population Data Science, 4(1), 1-11.

$3^{8}$ Carter et al., 'The Social Licence for Research'.

39 Aitken et al., 'Consensus Statement'. 
implicit purposes and goals. Inclusion and accessibility will broaden reach and two way communication - dialogue - is a necessary but not sufficient condition for impact. The latter can only be achieved if there is institutional buy-in, a commitment to respond to and utilise PE in governance and research. Given the challenges of assessing whether or not PE is impactful, something we discuss in the conclusion below, PE should be designed with impact in mind and be evaluated throughout. It is clear that you cannot straightforwardly get the right public and the right mechanism and be assured of meaningful and impactful PE. The choices are complicated and inflected with norms and goals that need to be explicitly stated and indeed challenged.

We now turn, as a conclusion, to review some of the outstanding issues that a critical approach to PE brings and make the case for robust evaluation.

\subsection{CONCLUSION}

The prominent emphasis on PE in relation to health research can be seen as a reflection of a wider resurgence of interest in PE in diverse policy areas. ${ }^{40}$ For example, Coleman and Gotzehave pointed to a widespread commitment to PE, conceived of as a mechanism for addressing problems in democratic societies. ${ }^{41}$ For Wilsdon and Willis, the emphasis on engagement represents a wider pattern whereby the 'standard response' of government to public ambivalence or hostility towards technological, social or political innovation is 'a promise to listen harder'. ${ }^{2}$

$\mathrm{PE}$ is not straightforward, and fulfilling the commitments of PE presents challenges and dilemmas in practice. There are many different ways of approaching PE, and these lead to different ideas of what constitutes success. There is no agreed best practice in evaluation; different rationales lead to different approaches to evaluation. Approaches underpinned by normative rationales will evaluate the quality of PE processes (Was it done well?); instrumental rationales lead to a focus on outcomes (Was it useful? Did it achieve the objectives?); and substantive rationales will assess the value added for participants or wider society (Did participants benefit from the process? Were there wider positive impacts?). Evaluation following substantive rationales is typically focussed on longer term outcomes, compared to evaluation following normative or instrumental rationales. Such longer term outcomes may be indirect and difficult to quantify or measure.

While the literature on methods of doing PE continues to proliferate, evaluation of PE remains under-theorised and underreported. The current evidence base is limited, but existing approaches to evaluating PE tend to reflect instrumental rationales and focus on direct outcomes of PE rather than substantive rationales and indirect, less tangible outcomes or impacts. ${ }^{43}$ Wilson and colleagues ${ }^{44}$ have observed that there is a tendency to focus on 'good news' in evaluating PE and that positivist paradigms shaping research projects or programmes can limit the opportunities to fully or adequately evaluate the complexities of PE as a social process.

$4^{\circ}$ M. Pieczka and O. Escobar, 'Dialogue and Science: Innovation in Policy-Making and the Discourse of Public Engagement in the UK', (2013) Science and Public Policy, 40(1), 113-126.

$4^{4}$ J. Gotze and S. Coleman, Bowling Together: Online Public Engagement in Policy Deliberation (London: Hansard Society, 2010).

$4^{2}$ Wilsdon and Willis, See-Through Science, p. 16.

43 J. P. Domecq et al., 'Patient Engagement in Research: A Systematic Review', (2014). BMC Health Services Research, $14(1), 89$.

44 P. Wilson et al., (2015) 'ReseArch with Patient and Public invOlvement: A RealisT evaluation - the RAPPORT study', (2015) Health Services and Delivery Research, 3(38), 1-9. 
This is significant as it means that while a variety of rationales and purposes are acknowledged in relation to PE, there is very limited evidence of the extent to which these are realised. This in turn has negative implications for the recognition - and consequently, the institutional support that $\mathrm{PE}$ receives. By providing evidence only of narrow and direct outcomes, instrumental approaches to evaluation obscure the varied and multiple benefits that can result from PE. While "the move from "deficit to dialogue" is now recognised and repeated by scientists, funders and policymakers [...] for all of the changing currents on the surface, the deeper tidal rhythms of science and its governance remain resistant'. ${ }^{45}$ Despite growing emphasis on dialogue and coinquiry, simplistic views of the relationship between science and the public persist ${ }^{4^{6}}$ and $\mathrm{PE}$ is often conducted in instrumental ways which seek to manufacture trust in science rather than foster meaningful dialogue. Greater reflection is required on the question of why publics are engaged rather than how they are engaged.

Finally, in designing, conducting and using PE in health research, we need to be reflective and critical, asking ourselves whether the issues are being narrowly defined and interpreted within existing frameworks (that often focus on privacy and consent). Does this preclude wider discussions of public benefit and the political economy of Big Data research for health? PE can and should improve health research and its regulation by questioning institutional practices and societal norms and using publics' contributions to help shape solutions.

45 Stilgoe et al., 'Why Should We Promote Public Engagement with Science?', 4.

${ }^{4}$ Kurath and Gisler, 'Informing, Involving or Engaging?'. 